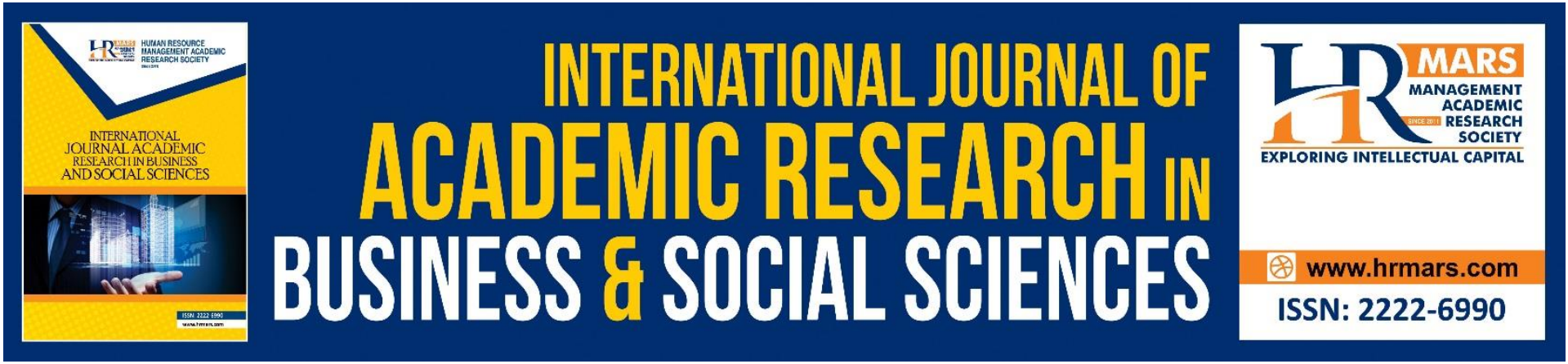

\title{
Theoretical Perspective on Employee Green Behavior
}

\section{Siti Norashikin Bashirun, Shereen Noranee, Zuhairah Hasan}

To Link this Article: http://dx.doi.org/10.6007/IJARBSS/v12-i1/12357 DOI:10.6007/IJARBSS/v12-i1/12357

Received: 18 November 2021, Revised: 25 December 2021, Accepted: 09 January 2022

Published Online: 29 January 2022

In-Text Citation: (Bashirun et al., 2022)

To Cite this Article: Bashirun, S. N., Noranee, S., \& Hasan, Z. (2022). Theoretical Perspective on Employee Green Behavior. International Journal of Academic Research in Business and Social Sciences, 12(1), 27822790.

Copyright: (c) 2022 The Author(s)

Published by Human Resource Management Academic Research Society (www.hrmars.com)

This article is published under the Creative Commons Attribution (CC BY 4.0) license. Anyone may reproduce, distribute, translate and create derivative works of this article (for both commercial and non0-commercial purposes), subject to full attribution to the original publication and authors. The full terms of this license may be seen

at: http://creativecommons.org/licences/by/4.0/legalcode

Vol. 12, No. 1, 2022, Pg. $2782-2790$

Full Terms \& Conditions of access and use can be found at http://hrmars.com/index.php/pages/detail/publication-ethics 


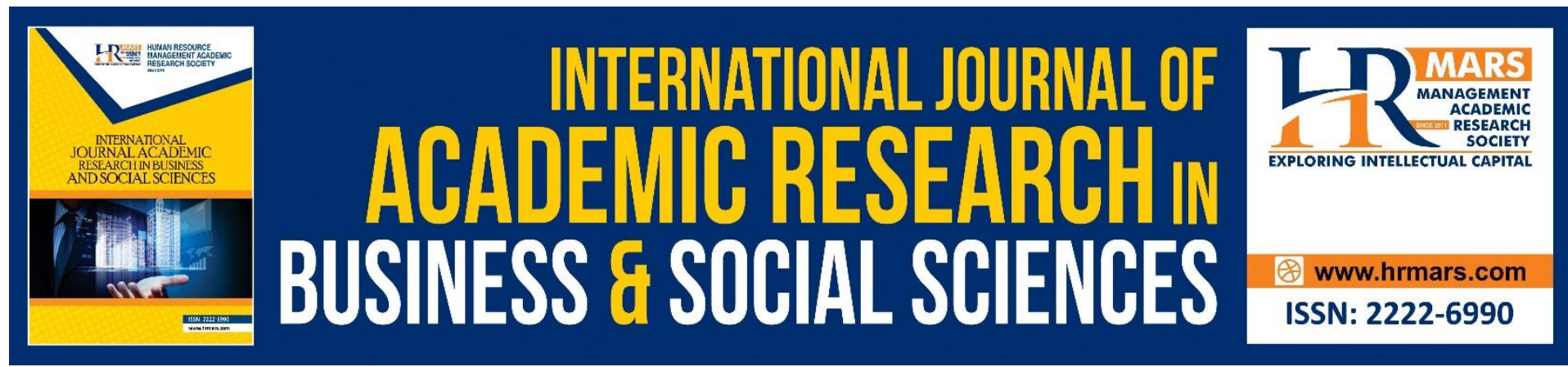

\title{
Theoretical Perspective on Employee Green Behavior
}

\author{
${ }^{1}$ Siti Norashikin Bashirun, ${ }^{2}$ Shereen Noranee, ${ }^{3}$ Zuhairah Hasan \\ ${ }^{1,3}$ Faculty of Business and Management, Universiti Teknologi MARA, Melaka \\ Malaysia, ${ }^{2}$ Faculty of Business and Management, Universiti Teknologi MARA, Selangor \\ Malaysia
}

\begin{abstract}
With the current global environmental problem, most organizations focus on environmental sustainability in their agenda. However, the strategy couldn't succeed without the employee's participation. The purpose of this paper is to explore the concept of employee green behavior and its theoretical implications. This paper is a conceptual paper that presents a new concept for environmentally sustainable organizations as a result of a literature study on management and psychology fields. The paper provides new insights and fruitful understanding and importance for the organization in fostering green behavior among employees at work.
\end{abstract}

Keywords: Employee Green Behavior, Environmental Sustainability

\section{Introduction}

Environmental challenges have now become a global phenomenon, with regional variations in the nature and scale of their influence. The growing environmental damages, as seen by global warming, environmental degradation, and ozone depletion, have prompted the corporation to prioritize environmental sustainability in its business strategy. Businesses organizations have made significant progress in integrating green practices and procedures to improve their corporate image, demonstrate their concern for the environment, and meet customer demand to gain a competitive edge (Asongu \& Odhiambo, 2021). The organization effort, on the other hand, does not operate universally and is dependent on employee environmentally friendly behavior, since employees are key actors in the path to environmental sustainability (Kollmuss and Agyeman, 2002; Ones \& Dilchert, 2012).

Organizations are intrinsically involved in climate change that is both in its causes and its solutions. According to statistics from the Department of Statistics, Malaysia (DOSM), the manufacturing sector accounted for $66.9 \%$ of total environmental protection spending in 2017, amounting to RM1,734.9 million. The study on green practices is getting to rise in Malaysia's context due to the urge on policy and agenda toward environmental sustainability. For example, in the Twelfth Malaysia Plan (2021 - 2025), the policy has been outlined to pursue green growth for sustainability and resilience that represent a commitment to the environment. Besides, environmental sustainability fits the current government policies on 
pursuing sustainable development goals (SDG) which have become the main agenda of ASEAN Vision 2025. Nevertheless, the commitment by the government alone would not be sufficient. Hence, long-term commitment must be involved from all businesses, stakeholders, and society.

Green behavior is primarily identified in the contexts of household and consumer behavior. For instance, (Zukauskien, 2017, Razali et al., 2020,) revealed household waste management separation behaviors. In the other context, scholars often studied green marketing for example (W Zhuang et al., 2021; Zaremohzzabieh, et al., 2021) on green purchase behavior, the consumer's green consumption (Pleming, 2016), and guest's intention on green hotel attributes (Le et al., 2019). However, the study of green behavior remains scarce in a work setting. In response to this, one of the strategies is greening the organization through employee behavioral change towards green behavior (Sonetti et al., 2019; Young et al., 2013). By encouraging green behavior at work might result in employee responsibility to help deal with the environmental impacts.

\section{Literature Review}

\section{Employee green behavior (EGB)}

EGB has been defined as an employee who engages in environmental activities that are beneficial for the organization which is derived from the definition of job performance (Ones \& Dilchert, 2012). Accordingly, Norton et al (2015) stipulated that EGB is a workplace-specific form of pro-environmental behavior. The authors also emphasize two types of EGB required and voluntary. Required EGB is delineated as green behavior performed within the context of employees' required job duties. It is also known as task-related EGB which includes obliging to organizational policies, changing methods of work, and creating sustainable products and processes. The concept of required EGB is like task performance, which is defined as the activities formally identified as part of a person's job that contributes to the technical core of an organization (Tian \& Zhang, 2019). Meanwhile, voluntary EGB has been defined as green behavior involving personal initiative that exceeds organizational expectations (Norton et al., 2015).

Fostering EGB at work could be one of the factors that help to deal with the environmental issues (Lamm et al., 2013). Consequently, EGB is one of the strategies adopted by organizations to improve their environmental sustainability performance (DuBois \& Dubois, 2012). Employees' behaviors such as, storing office supplies, separating waste, using teleconference, reusing and recycling paper, and sharing environmental sustainability information between co-workers are among the behavior that could foster environmental concern at work (Kim et al., 2017; Kim et al., 2019).

Several empirical studies have shown a significant outcome on the importance of EGB for organizational environmental sustainability (Bohlmann et al., 2018; Po, 2019; Unsworth et al., 2021). For example, the study by Luu (2017) revealed that EGB help improve the company's image and benefits organizations directly by conserving resources and energy for cost reduction and indirectly by preserving the natural environment for organizational sustainability. In addition, Suganthi (2019) found that the corporate social responsibility (CSR) initiative has a strong relationship with green practices in the company that indirectly enhances the corporate image to the stakeholders. Similarly, the right way to cultivate a 
positive public image and sound corporate social responsibility (CSR) ethics is to follow green conduct (Hens et al., 2018).

Recognizing that environmental problem is mainly caused by industries directly or indirectly, as such, environmentally friendly behavior should be explored among employees as it is an important aspect to reach sustainability for the organization (Norton et al., 2014; Suganthi, 2019). Thus, the concept of green behavior in the workplace has emerged.

\section{The Theoretical Perspective of Employee Green Behavior}

As pro-environmental behavior has received growing attention from most scholars, questions about the key factors that encourage individuals to adopt pro-environmental behavior have increasingly occupied the interests of researchers. Among these researches, several models were developed to examine pro-environmental behavior with distinct theoretical frameworks.

Behavioral change theories attempt to explain why behavior changes. These theories serve to understand better those factors associated with maximizing adherence to positive physical activities and lifestyle behaviors at the individual, community, and population levels. Therefore, a wide range of factors that impact people's decision-making processes can be taken into consideration by behavioral theories (Morris et al., 2012). These behavioral theories can be used to describe and predict human behavior, thereby increasing policy formulation and behavior intervention effectiveness.

Several theories have been proposed to understand and address green behavior in the workplace setting. While some theories have focused on individual intention to perform EGB such as the theory of planned behavior (TPB) (Greaves et al., 2013), others like selfdetermination theory (SDT) that focuses on motivation towards environmental behavior (Budzanowska-Drzewiecka \& Tutko, 2021) and social exchange theory (SET) which determine the pro-environmental behavior and organization performance (Paillé \& Boiral, 2013a). Furthermore, another such as value-belief-norm (VBN) has explained individual choices on pro-environmental behavior that can be driven by personal norms (Po, 2019). Each of these theories has viewed employee pro-environmental behavior differently, but put together, all of these theories have helped to gain a deeper understanding of employee green behavior at the workplace.

According to Ajzen (1991), the theory of planned behavior (TPB) explains behavioral intentions using three factors: attitude, subjective norms, and perceived behavioral control. Previous studies often refer to this theory in explaining environmental behavior intention in numerous contexts. Recent literature had utilized TPB in exploring significant relationships on environmental behavior (Muniandy et al., 2021; Zhang et al., 2019). For instance, subjective norms may influence the behavioral intention particularly about the waste separation behaviors among households (Razali et al., 2020). Meanwhile, a study by Zhang et al (2019) revealed that TPB had a significant effect on purchase intention for green products. In particular, attitude and perceived behavior control had positive and significant effects on customer purchase intention for buying eco-friendly products. According to TPB, individuals holding positive attitudes toward environmental engagement and environmental concern tend to have normative support for pro-environment behavioral intentions (Ibrahim et al., 2021). In contrast, Wang (2016) argued that the three components of TPB were less accurate in explaining the employee commitment towards green behavior at the food restaurant. Additionally, several researchers have claimed that while using the TPB for 
determining sustainable behavior, researchers should consider adding supplementary predictors of behavioral intention (Po`skus, 2015). Nevertheless, TPB has inadequacy in predicting green behavior due to the cognitive and non-cognitive nature of green behavior (Singaralingam, 2015).

The previous scholars embedded the self-determination theory (SDT) to identify what motives usually drive EGB. SDT developed by Deci and Ryan (1985) is a broad theory explaining human motivation in terms of intrinsic and extrinsic factors. In addition, this theory shows how certain characteristics of workplaces such as leadership roles and workplace spirituality can create environments that lead to the employee's higher intrinsic motivation to engage in environmental behavior. As advocated by Fatoki (2019), green behavior at work could be inspired through a leader role in motivation and support. Moreover, Aitken et al. (2016) stated that utilizing SDT can elucidate green behavior and result in increasing individuals' autonomous motivation toward the environment and potentially leading to a larger environmental impact. For instance, the researcher suggested that employees are motivated to support their organizational environmental sustainability initiatives, and undoubtedly recognize that they can get rewards and avoid punishment by demonstrating green behavior (Graves et al., 2019). Furthermore, employees who work in organizations with a strong pro-environmental climate as well as having strong autonomous support will have a higher level of autonomous motivation and eventually engage in more green behavior in the workplace (Id et al., 2019). Hence, it is postulated that SDT is more dominant in motivating employee green behavior at work.

Social exchange theory (SET) has been employed in environmental sustainability studies. The theory explains human exchange relations and refers to the mutual relationship between people (Emerson, 1976). For example, when individual employees in the workplace feel supported and valued, they are most likely to reciprocate by demonstrating the desired result of their work outcomes (Lavelle, McMahan, \& Harris, 2009). Accordingly, it happens when employees perceive benefits from what the organization had provided to them and they feel committed to responding (Jiang et al., 2012). When employees feel supported and satisfied in their workplace, in exchange, this will encourage them to engage in organizational citizenship behavior for the environment (OCBE) and finally enhance the organizational environmental sustainability (Paillé \& Boiral, 2013a). On the other hand, Priyankara et al., (2018) had integrated SET, SDT, and theory of normative conduct (TNC) in examining leader's role, autonomous motivation, and perceived group's green climate on organizational citizenship behavior for the environment (OCBE). This multi-theory perspective confirmed that the exchange relation and in a combination of self-determination and normative to be significant as antecedents of OCBE. Based on the literature, OCBE is seen as one of the reciprocal behaviors in environmental studies and it shows that SET is more dominant with OCBE.

Accordingly, Stern (2000) proposed the value-belief-norm theory (VBN), which is another theoretical framework applicable to study pro-environmental behavior. This theory is based on the three components namely values, beliefs, and norms which are essential to environmentalism, such as values and environmental conservation worldview. The moral theory of VBN includes norm activation theory (Stern et al., 1999) and is related to the strength of self-enhancement values, and this theory practices more complex associations than the TPB in describing pro-environment behavioral intentions. Ture and Ganesh (2018) choose the VBN theory as their basis in the study to determine the green behavior model among Indian manufacturing employees. They argue that organizational variables (corporate 
environmentalism) and social-psychological variables (social norm) are predictors for workplace green behavior. In addition, Choi et al. (2015) incorporated subjective norms and green trust into consumers' intention to revisit the green hotel. However, this study only tested the model using the "value" component and omit the other two; beliefs and norms. Similarly, the norm activation process is significant on consumer's eco-innovation and portrays a positive change in green direction to increase eco-friendly transportation (Nordlund et al., 2016). In line with this, several studies using VBN theory are found to use a single component to investigate the determinants of green behavior (Norton, 2016; Yuriev et al., 2018).

Taking into account the contexts and background for the research in the present study, a selection of these theories is expounded in the following subsections. The presented theory played an important role in the hypothesis development and explanation of the proposed study. Table 1.1 offers a view of the theories within employee green behavior research and to fill the theoretical gap in future studies.

Table 1.1 Theories in Employee Green Behavior Perspective

\begin{tabular}{|l|l|l|}
\hline No & Author & Theory \\
\hline 1 & Greaves, Zibarras, \& Stride (2013) & Theory of Planned Behaviour (TPB) \\
\hline 2 & Paillé \& Boiral (2013b) & Social Exchange Theory (SET) \\
\hline 3 & Ture \& Ganesh (2014) & Value-Belief-Norm Theory (VBN) \\
\hline 4 & Sawitri et al. (2015) & Social Cognitive Theory (SCT) \\
\hline 5 & Temminck et al. (2015) & $\begin{array}{l}\text { Extension of Social Exchange Theory } \\
\text { (SET) }\end{array}$ \\
\hline 6 & Raineri et al. (2016) & Social Exchange Theory (SET) \\
\hline 7 & Wang, (2016a) & Theory of Planned Behaviour (TPB) \\
\hline 8 & Saifulina \& Carballo-Penela (2017) & Social Cognitive Theory (SCT) \\
\hline 9 & Wesselink et al. (2017) & Theory of Planned Behaviour (TPB) \\
\hline 10 & Priyankara et al. (2018) & $\begin{array}{l}\text { Social Exchange Theory (SET) } \\
\text { Self Determination Theory (SDT) } \\
\text { Theory od Normative Conduct (TNC) }\end{array}$ \\
\hline 11 & Ghazali, Nguyen, \& Mutum, (2019) & Value-Belief-Norm Theory (VBN) \\
\hline 12 & Fatoki (2019) & Self Determination Theory (SDT) \\
\hline 13 & Id et al. (2019) & Self Determination Theory (SDT) \\
\hline 14 & Pinzone et al. (2019) & $\begin{array}{l}\text { Ability-Motivation-Opportunity theory } \\
\text { (AMO) }\end{array}$ \\
\hline 15 & Suganthi (2019) & Stakeholder Theory (CSR) \\
\hline 16 & Tian \& Zhang (2019) & $\begin{array}{l}\text { Self Determination Theory (SDT) } \\
\text { Theory of Normative Conduct (TNC) }\end{array}$ \\
\hline 17 & Zhao \& Zhou (2019) & Social Identity Theory (SIT) \\
\hline 18 & Zhao \& Zhou (2020) & Social Cognitive Theory (SCT) \\
\hline 19 & Razali et al. (2020) & Theory of Planned Behaviour (TPB) \\
\hline 20 & Ibrahim et al. (2021) & Theory of Planned Behaviour (TPB) \\
\hline
\end{tabular}

\section{Implications and Future Agenda}

From the above-aforementioned literature, it is speculated that several theories are applicable in green behavior study. In accordance with the workplace context, it is still an 
avenue for future study to discover other theories due to numerous influencing factors on determining EGB. Recent studies by (A. Kim, 2014; Norton, 2016; Saleem et al., 2020) propose to integrate and explore the multi-level perspective theory that is relevant to the study context.

Organizations will enhance environmental awareness and knowledge among employees and finally help achieve and preserve organizational environmental sustainability by fostering green behavior at the workplace (Zhang et al., 2019). Moreover, environmental behavior at work has the potential to provide significant implications for environmental protection because human activity within organizations is a major cause of ecological problems (Robertson \& Barling, 2013). Consequently, there is a need to understand the nature of green behavior more clearly as it occurs specifically in the work setting that considers the organizational context as a contributing factor and recognizes that green behavior at work constitutes a particular form of job performance (Norton et al., 2015). Therefore, research on green behavior in the work setting is needed to investigate the factors that influence, the barriers to promotion, and the intervention that makes employees engage in such behavior (Unsworth et al., 2021).

\section{Conclusions}

By understanding these employee green behaviors, it will help to promote an environmental sustainability culture at the workplace (Rameshwar \& Ganesh, 2014). To date, there is a paucity of studies regarding the antecedents of green behavior among employees (Boiral \& Paille, 2013; Norton et al., 2012), and this research will serve as a base for future studies on green behavior in Malaysia.

Concern should also be given to the environmental issue in the workplace since it is less emphasized by employers and employees. The law and regulations imposed are insufficient to educate people to engage in environmentally friendly behaviors at work. Therefore, fostering EGB could be one of the ways that can potentially help in dealing with this issue. This article review will enhance the body of knowledge of employees' green practices that the organizations will benefit from with a more comprehensive understanding of the relationship, especially in Malaysia.

Finally, this review paper had aimed to describe issues and factors that lead to green behavior among employees at work. More importantly, this paper contributes to organizational strategy and management and extends the literature on organizational environmental sustainability by fostering employees' green behavior at work. As a result, future scholars will have several opportunities to contribute to this topic and further their understanding of employees as key agents in achieving environmental sustainability.

\section{Acknowledgments}

The authors acknowledge that this research was made possible through the Skim Geran Dalaman TEJA2021 (GDT2021/1-24), Universiti Teknologi MARA Cawangan Melaka.

\section{Corresponding Author}

Zuhairah Hasan

Faculty of Business and Management, Universiti Teknologi MARA, Melaka

Email: zuhairah612@uitm.edu.my 


\section{References}

Asongu, S. A., \& Odhiambo, N. M. (2021). Enhancing governance for environmental sustainability in sub-Saharan Africa. Energy Exploration \& Exploitation, 39(1), 444-46

Bohlmann, C., Van Den Bosch, J., \& Zacher, H. (2018). The relative importance of employee green behavior for overall job performance ratings: A policy-capturing study. Corporate Social Responsibility and Environmental Management, 1-7.

https://doi.org/10.1002/csr.1516

Boiral, O., \& Paille, P. (2012). Organizational Citizenship Behaviour for the Environment: Measurement and Validation. 431-445. https://doi.org/10.1007/s10551-011-1138-9

Francoeur, V., Paillé, P., Yuriev, A., \& Boiral, O. (2019). The Measurement of Green Workplace Behaviors : A Systematic Review. https://doi.org/10.1177/1086026619837125

Kollmuss, A., \& Agyeman, J. (2002). Mind the Gap: Why do people act environmentally and what are the barriers to pro-environmental behavior? Environmental Education Research. https://doi.org/10.1080/13504620220145401

Lamm, E., Tosti-Kharas, J., \& Williams, E. G. (2013). Read This Article, but Don't Print It: Organizational Citizenship Behavior Toward the Environment. Group and Organization Management. https://doi.org/10.1177/1059601112475210

Le, H., Trang, T., Lee, J., \& Han, H. (2019). How do green attributes elicit pro-environmental behaviors in guests ? The case of green hotels in Vietnam. Journal of Travel \& Tourism Marketing, 00(00), 1-15. https://doi.org/10.1080/10548408.2018.1486782

Luu, T. T. (2017). CSR and organizational citizenship behavior for the environment in the hotel industry. International Journal of Contemporary Hospitality Management, 29(11), 28672900. https://doi.org/10.1108/IJCHM-02-2016-0080

Norton, T. A., Parker, S. L., Zacher, H., \&, \& Ashkanasy, N. M. (2015). Employee Green Behavior: A Theoretical Framework, Multilevel Review, and Future Research Agenda. Organization and Environment, 28(1), 103-125.

https://doi.org/10.1177/1086026615575773

Ones, D. S., \& Dilchert, S. (2012). Environmental Sustainability at Work: A Call to Action. Industrial and Organizational Psychology, 5(4), 444-466. https://doi.org/10.1111/j.1754-9434.2012.01478.x

Organ, D. W., Podsakoff, P. M., \& MacKenzie, S. B. (2006). Organizational citizenship behavior: Its nature, antecedents, and consequences. In Organizational Citizenship Behavior: Its Nature, Antecedents, and Consequences. https://doi.org/10.4135/9781452231082

Pleming, K. J. (2016). Consumers' Perceptions and Attitudes Towards Firms; Green Marketing Initiatives: How Do They Influence Green Consumption? 1-201. https://eprints.qut.edu.au/93575/1/Katrina_Pleming_Thesis.pdf

Po, M. S. (2019). The Importance of Environmental Knowledge for Private and Public Sphere Pro-Environmental Behavior: Modifying the Value-Belief-Norm Theory.

Robertson, J. L., \& Barling, J. (2013). Greening organizations through leaders ' influence on employees' pro-environmental behaviors. Journal of Organizational Behavior, J. Organiz. Behav., 34(February), 176-194. https://doi.org/10.1002/job.1820

Sonetti, G., Brown, M., \& Naboni, E. (2019). About the triggering of UN sustainable development goals and regenerative sustainability in higher education. Sustainability (Switzerland), 11(1), 1-17. https://doi.org/10.3390/su11010254

Suganthi, L. (2019). Examining the relationship between corporate social responsibility, performance, employees' pro-environmental behavior at work with green practices as mediator. Journal of Cleaner Production. https://doi.org/10.1016/j.jclepro.2019.05.295 
Tian, H., \& Zhang, J. (2019). The relationship between pro-environmental attitude and employee green behavior: the role of motivational states and green work climate perceptions. Environmental Science and Pollution Research.

Unsworth, K. L., Davis, M. C., Russell, S. V., \& Bretter, C. (2021). Employee green behavior: How organizations can help the environment. Current Opinion in Psychology, 42, 1-6. https://doi.org/10.1016/j.copsyc.2020.12.006

Young, W., Davis, M., Mcneill, I. M., Malhotra, B., Russell, S., Unsworth, K., \& Clegg, C. W. (2013). Changing Behaviour: Successful Environmental Programmes in the Workplace. Business Strategy and the Environment. https://doi.org/10.1002/bse.1836

Zhang, Y., Luo, Y., Zhang, X., \& Zhao, J. (2019). How Green Human Resource Management Can Promote Green Employee Behavior in China: A Technology Acceptance Model Perspective. Journal of Sustainability, 11.

Zukauskien, R. (2017). Predicting adolescents' recycling behavior among different big five personality types. 54. https://doi.org/10.1016/j.jenvp.2017.10.003 